\title{
Clinical Profile of Lymphatic Malformation from One Oral and Maxillofacial Center in Sudan
}

\author{
Omar Amir El Hag1, Elneel Ahmed Mohamed Ali2 ${ }^{*}$, Musadak Ali Karrar Osman ${ }^{3}$ \\ ${ }^{1}$ OMF Surgery, Gazira University, Wad Medani, Sudan \\ ${ }^{2}$ OMF Surgery, Faculty of Dentistry, University of Khartoum, Khartoum, Sudan \\ ${ }^{3}$ OMFs Section, Dental Department, King Faisal Specialist Hospital \& Research Center, Riyadh, KSA \\ Email: *Elneel.mohmed@yahoo.com
}

How to cite this paper: El Hag, O.A., Ali, E.A.M. and Osman, M.A.K. (2017) Clinical Profile of Lymphatic Malformation from One Oral and Maxillofacial Center in Sudan. Open Journal of Stomatology, 7, 345352.

https://doi.org/10.4236/ojst.2017.78029

Received: June 3, 2017

Accepted: July 31, 2017

Published: August 3, 2017

Copyright $\odot 2017$ by authors and Scientific Research Publishing Inc. This work is licensed under the Creative Commons Attribution International License (CC BY 4.0).

http://creativecommons.org/licenses/by/4.0/

\section{(c) (i) Open Access}

\begin{abstract}
Background: Lymphatic malformations are developmental defects of the lymphatic system. They are frequently present at birth and are most commonly found in the head and neck regions. The aim of the study was to investigate the clinical presentation of head and neck Lymphatic malformations in relation to, age, gender, color and site of distribution. Methods. This is a retrospective descriptive study, where the record of the patient diagnosed as lymphatic malformation at the Department of Oral and Maxillofacial Surgery at Khartoum Teaching Dental Hospital, during the period of 2005 to 2008 where retrieved and analysed. Result. A cervicofacial lymphatic malformation was found more common in females than in males with a ratio of 11:9. The mean age was $14 \pm 10$ years, with lip and tongue being the most common sites, followed by the buccal mucosa in the intraoral site and neck in the posterior triangle was the most common site for extraoral site (30\%). It was found that the bluish color was the commonest presenting color in oral lymphangioma followed by red pink color. Conclusion: Females are more affected than males, while infants and children were more affected than other age groups. The bulks of the patients were presented with soft swelling, blue to normal colour in the lip, neck and in the tongue. Further prospective studies are needed to evaluate the clinic picture and treatment outcome.
\end{abstract}

\section{Keywords}

Lymphangioma, Lymphatic Malformation, Maxillofacial Tumor, Sudan

\section{Introduction}

Lymphatic malformations (LM) are hamartomatous disorder of the lymphatic system. It was believed that it is due to entrapment of lymphatic tissues during 
embryogenesis [1]. So it is considered as congenital malformation rather than true neoplasm [2]. There were reports that it has a familial tendency with no reports of malignant transformation [3]. It can be found in any site of the body but most frequently involved head and neck with over $60 \%$. Of these, up to $50 \%$ occurred in the oral cavity where tongue is the most common site followed by buccal mucosa. There is no gender predilection and about $50 \%$ of the malformation is noted at birth and $90 \%$ at 2 years of age [4].

According to Alqahtani et al. $41 \%$ of the lesions are diagnosed on the bases of history and clinical appearance alone. Therefore, the clinical picture and appropriate knowledge of distribution and frequency of LM are very important [5].

Histologically, it can be classified into three types according to the size of lymphatic vessels into capillary, cavernous and cystic type [6]. However, the three types can be found in one lesion [4]. Intra-orally, LM exhibited cavernous type most commonly and the neck showed the cystic type [6].

In Sudan, a country with limited medical resources and low income, the clinical picture can be the only way to make a definitive diagnosis for such malformation before any treatment intervention.

There was no previous published epidemiological study had been conducted in Sudan to evaluate the clinical profile for lymphatic malformation. This study intended to assess this malformation among patients presented to oral and maxillofacial department in Khartoum Teaching Dental Hospital.

\section{Patients and Methods}

The materials of this study were patients attending the Department of Oral and Maxillofacial Surgery at Khartoum Teaching Dental Hospital (KTDH), complaining of lymphatic malformation. The data retrieved from the hospital records in the period 2005-2008. Data collection sheets stating the age, gender, site, consistency and color were used. Records missing one of these variables where excluded from the study. The patients were classified according to age into four groups: Group (1) from birth to 10 years; Group (2) from 11 to 20, Group (7) from 21 to 30 and lastly Group (4) from 31 and above.

Ethical approval was obtained from ethical committee review board and research unit in KTDH.

Data was analyzed using the Statistical Package for Social Science (SPSS) version 13 for windows software with the help of biostatistician. Descriptive statistics by mean of means, standard deviation and frequency distribution were calculated.

\section{Results}

A total of 20 cases of lymphangioma were found in the records of KTDH during the period (May 2005 to November 2008). The age of 2 years was the most common age at presentation with mean age of the patients was 14.8 (ranging 
from 6 months to $49 \mathrm{yrs})$. Eleven cases were females (55\%), and the rest were males (45\%) (Figure 1).

In the first age group ( $<1-10$ years), there were 10 cases accounting for $50 \%$ of the whole series. In the second group $(11-20)$ there were 4 cases accounting $20 \%$ of the series. In the third group $(21-30)$, and the fourth group (31 - 40), there were 3 cases in each accounting for $15 \%$ of the series (Figure 2).

The sites involved are the neck, lip, cheek and the tongue. The neck and lip were the most common sites where six cases were found in each, accounting for $30 \%$, followed by the tongue and the cheek, four cases in each (Figure 3 ).

The consistency of oral and cervicofacial lymphangioma was recorded; 11 patients presented with soft swelling representing (55\%), seven patients with fluctuant swelling (35\%) and one patient presented with rubbery mass and one firm (Figure 4).

The color of the lymphangioma was different according to the anatomical site. Blue and normal skin textures were the most common colours where six cases (30\%) were found in each. The second common color was pink by four cases
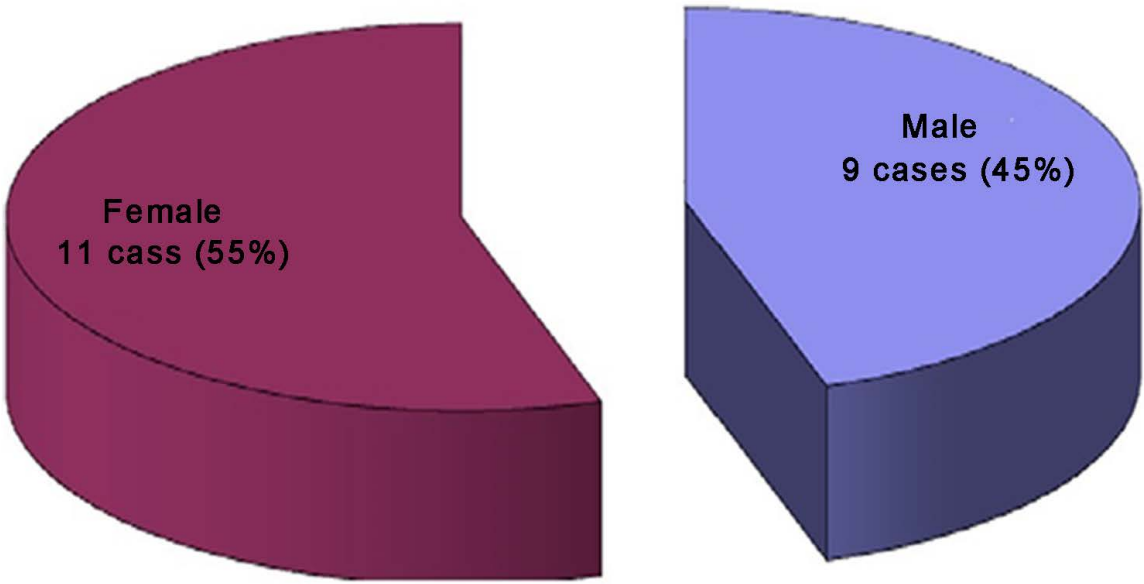

Figure 1. Distribution of Lymphatic malformation among gender.

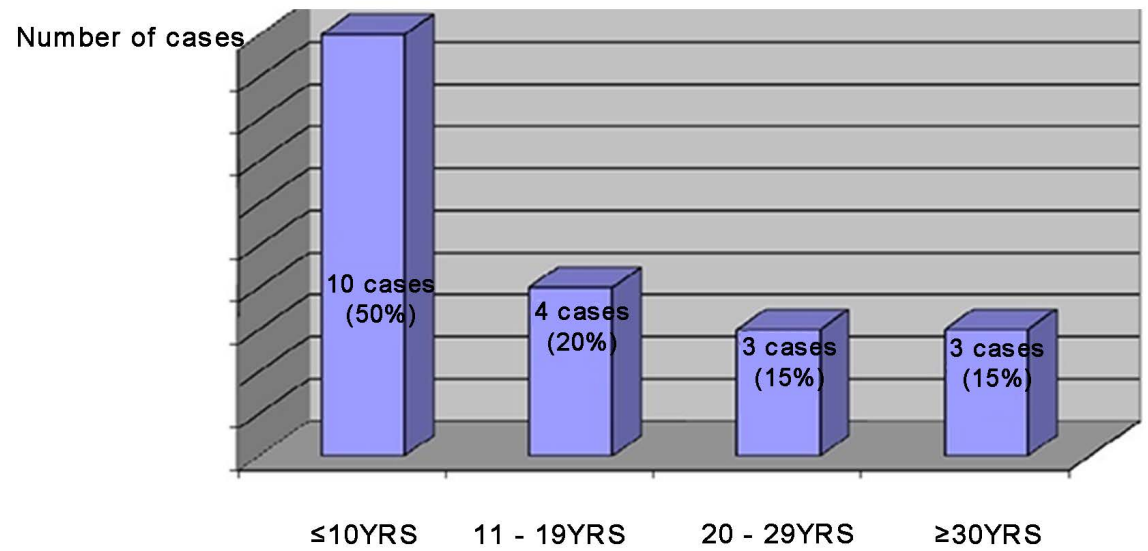

Figure 2. Distribution of Lymphatic malformation among different age groups. 


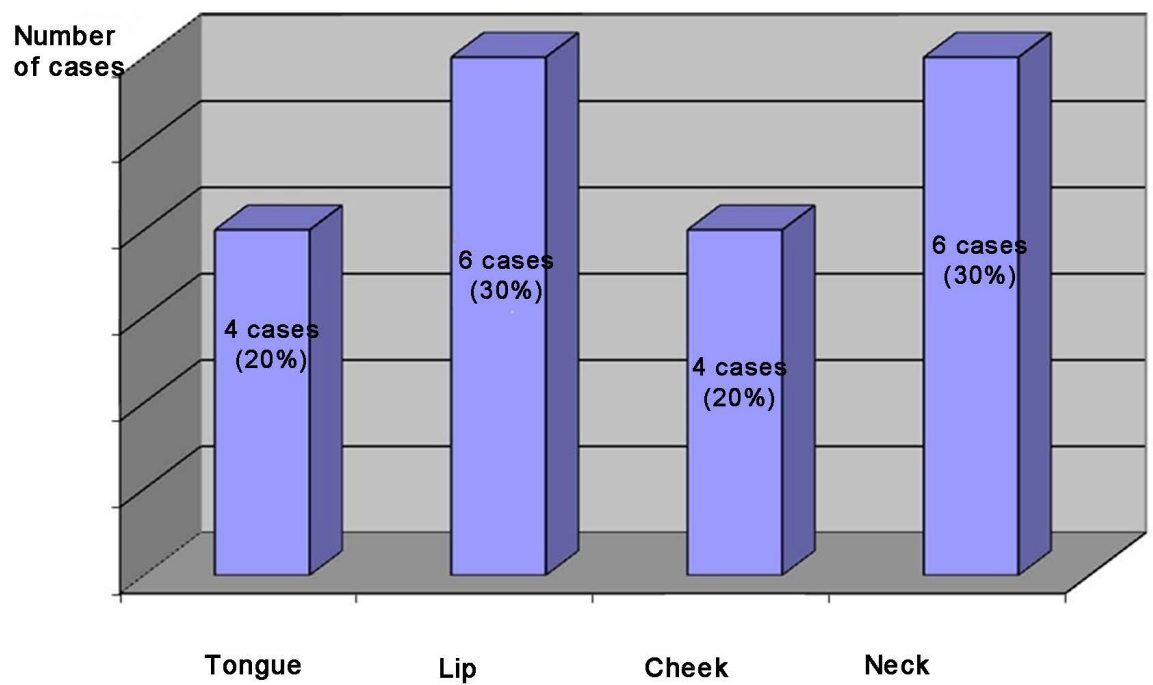

Figure 3. Site distribution of Lymphatic malformations.

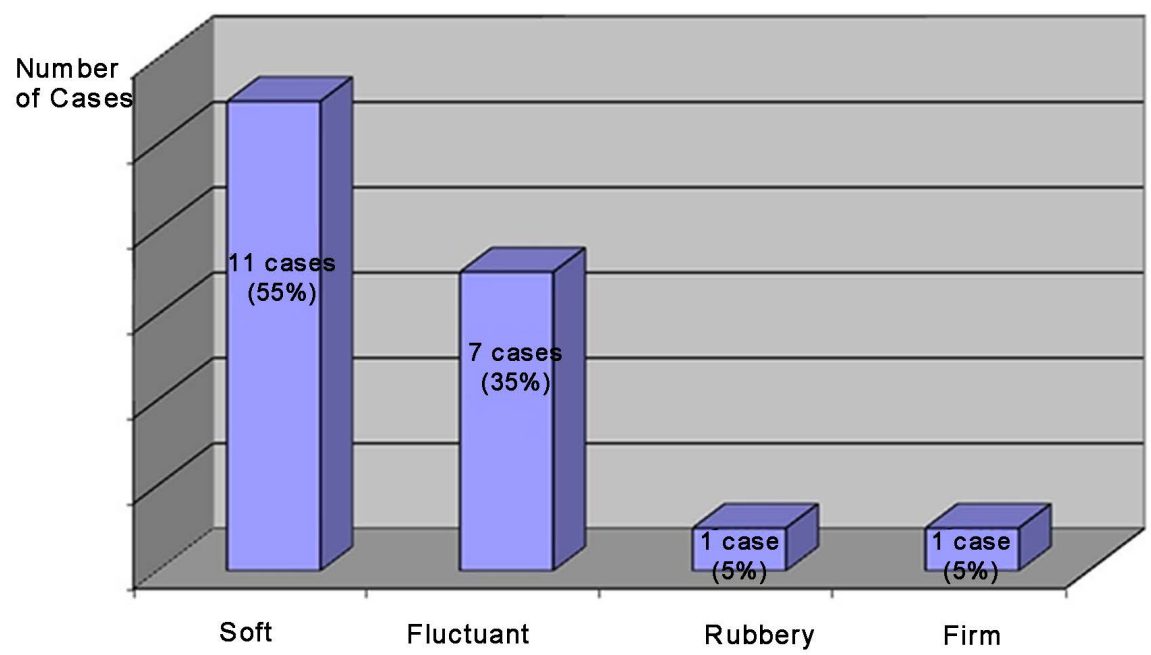

Figure 4. Consistency of Lymphatic malformation.

(20\%). The red and yellowish colours were also found, each representing two cases (10\%) of the series (Figure 5).

In the lip, the most common colors were the blue and normal skin accounting for two cases for each. In the neck, the commonest colours were blue, pink and normal skin colour accounting for two cases. In the tongue, the blue color was accounting for 2 cases, and the yellowish and the pink colours, each accounting for 1 case. In the cheek, the colors of the lymphangioma were the red and the yellow, each representing 25\% (Figure 6).

\section{Discussion}

Lymphatic malformation (LM) have been traditionally been referred to as lymphangioma despite absences of significant endothelial mitotic activity.

Lymphatic malformation can occur in any site of the body and have preference to head and neck region which account for $50 \%$ to $75 \%$ of all cases [4]. It is 


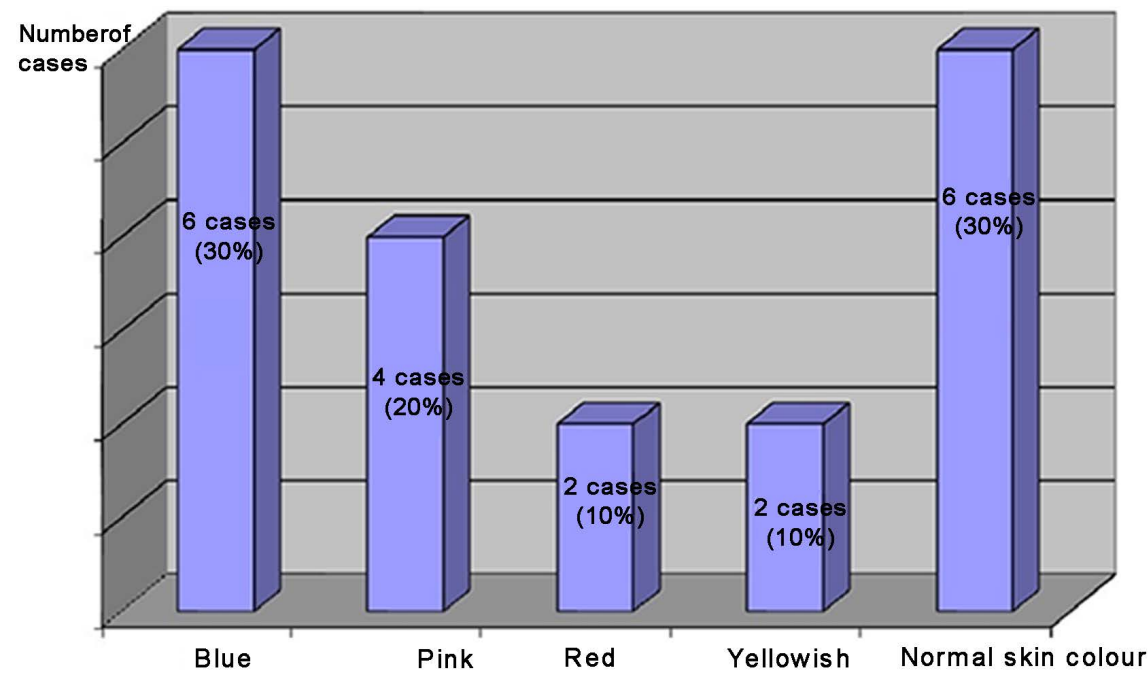

Figure 5. The color of Lymphatic malformation.

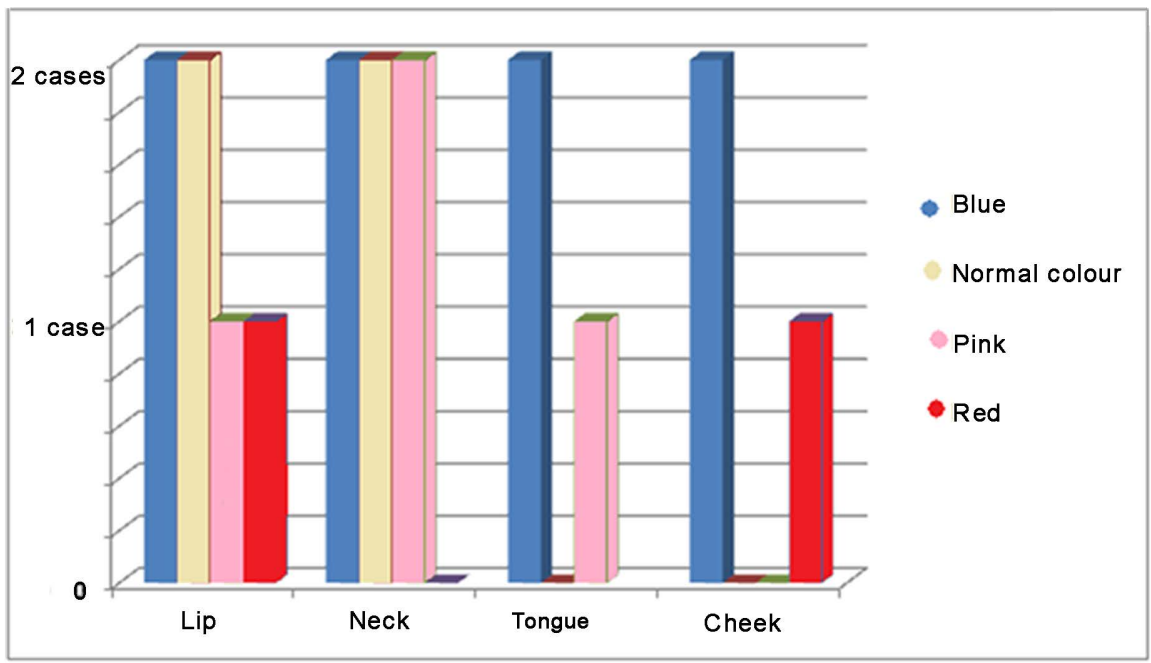

Figure 6. The colors and the sites of Lymphatic malformation.

a hemartomtous lesion that account for $6 \%$ of all benign, $11 \%$ of all tumors of maxillofacial area and 9\% of all soft tissue tumor among children [5].

The exact pathogenesis is unknown. Some authors consider it as malformation and others considered it as a true neoplasm. It had been suggested that, the proximity of the blood and lymphatic vessels to each other made that confusion. Recently, a sialoglycoprotien known as $\mathrm{d} 2-40$ has been found to be expressed in the endothelium of normal lymphatic vessels and lymphatic malformation and not in the blood vessels. So it may play as a marker in the future to differentiate between them [7].

Up to $60 \%$ of LM cases diagnosed at birth and $90 \%$ at the age of two years [5]. Moreover, in Brennan et al. series, the age was ranging from 2 to 84 year compare [2]. In this series, the most common presenting age was 2 years ranging from 6 months to $49 \mathrm{yrs}$ with mean age of 14.7 year. 
The study of Alqahtani reported slight predominance (52.6\%) in boys [5]. However, the current result showed slight girls predominance (11 cases, 55\%). This gender differences is minimal, and due to rarity of this lesion, a larger case series or meta-analysis may verified such variation.

In the oral and maxillofacial area, it most commonly occurs at posterior triangle that may extend to involve the oral cavity superiorly or inferiorly to reach the mediastinum. Generally, it does grow slowly but it may rapidly grow following upper respiratory tract infection or accidental trauma. This fact can be justified by incensing lymphatic production or secondary infection of malformation [4].

According to Filston et al. the incidence of lymphatic malformation is ranging from 1.2 to 2.8 per 1000 newborn [8]. It is rarely occurred in the oral cavity, and when occurred the most common site is tongue followed by buccal mucosa, where lip being a rare site of occurrence with approximately $6 \%$ of all oral lymphangioma [2]. Interesting in our series, the lip was the most common site of occurrence with the neck by $30 \%$ for each.

The most common sign is mass that is not present at birth and noticed later which may induce by upper respiratory infection or trauma. This will lead to the second and third most common presenting symptoms that are respiratory obstruction and feeding problem [9].

According to Guarisco et al., the soft fluctuant mass was the most common consistency types with $90 \%$ and the rest are rubbery to firm masses which is consisting with our finding. It is usually compressible lobulated, and ill-defined mass which is movable and not attached to overlying skin or mucosa [9].

It is known that the clinical color of L.M is differing from site to site depending on the lesion extension. Superficial lesion tends to be pinkish to blue while deep lesions are commonly described as normal in color [10]. In current study, there was a variation in the color which can be justified by the depth of L.M (Figure 5 \& Figure 6). Furthermore, in Sudan, there is different ethnic group with different skin color ranging from black to white which also may affect the clinical appearance.

The imaging by mean of soft tissues radiograph evaluates the soft tissues. CT scan and ultrasonography, helps in determining the consistency and MRI in the extension of the lesion and its proximity to vital structures, in determining whether the lesion contains a vascular component, and is used to assess recurrence in treated lesions. FNAC aid in differentiating between LM and other fluid fill lesions [5].

Furthermore, a Practical classification subtypes the LM into macroscopic, microscopic or combined. This classification based on CT scan or MRI using a volume as measure. Macroscopic LM consists of one or more cyst all of which are greater than $2 \mathrm{cc}$ [11]. Moreover, it can be classified based on ultrasonography by measuring the diameter of the cyst. LM with macroscopic type have predominant cyst with diameter more than $1 \mathrm{~cm}$ [12].

The treatment plan should consider important factors. These factors include type, size, anatomical involvement site and infiltration to the surrounding tissues. 
The treatment modalities consist of aspiration, surgical excision, sclerotherapy and medications. Some authors suggest observation as conservative management. Alqutham et al. suggested the indication of observation is asymptomatic patient or a child with a large LM when important structures at risk [5]. They also suggest that the interlesion injection is indicated in case of resection is not possible or a symptomatic recurrent lesion that is not easily excised [5]. Yet, $12 \%$ of the recurrent lesion may regress spontaneously, a point which should be considered in the management plan [5].

\section{Conclusion}

The present study showed that the oral lymphangioma was high in number among Sudanese patients who presented to department of oral and maxillofacial surgery, Khartoum Teaching Dental Hospital. Females are more affected than males, while infants and children were more affected than other age groups. The bulks of the patients were presented with swelling in the neck, lip and in the tongue. More prospective studies are needed to evaluate more clinical presentations of lymphatic malformations, the treatment modalities and the outcome.

\section{References}

[1] Bill, A.H.J. and Sumner, D.S. (1965) A Unified Concept of Lymphangioma and Cystic Hygroma. Surgery, Gynecology \& Obstetrics, 120, 79-86.

[2] Brennan, T.D., Miller, A.S. and Chen, S.Y. (1997) Lymphangiomas of the Oral Cavity: A Clinicopathologic, Immunohistochemical, and Electron-Microscopic Study. Journal of Oral and Maxillofacial Surgery. Official Journal of the American Association of Oral and Maxillofacial Surgeons, 55, 932-935. https://doi.org/10.1016/S0278-2391(97)90062-8

[3] Gallagher, P.G., Mahoney, M.J. and Gosche, J.R. (1999) Cystic Hygroma in the Fetus and Newborn. Seminars in Perinatology, 23, 341-356. https://doi.org/10.1016/S0146-0005(99)80042-1

[4] Neville, B.W.D.D., Allen, C.M. and Bouquot, J.E. (2009) Oral and Maxillofacial Pathology. 3rd Edition, W.B. Saunders, Philadelphia.

[5] Alqahtani, A., Nguyen, L.T., Flageole, H., Shaw, K. and Laberge, J.M. (1999) 25 Years' Experience with Lymphangiomas in Children. Journal of Pediatric Surgery, 34, 1164-1168. https://doi.org/10.1016/S0022-3468(99)90590-0

[6] Mosca, R.C., Pereira, G.A. and Mantesso, A. (2008) Cystic Hygroma: Characterization by Computerized Tomography. Oral Surgery, Oral Medicine, Oral Pathology, Oral Radiology, and Endodontics, 105, e65-e69. https://doi.org/10.1016/j.tripleo.2008.01.015

[7] Nagaoka, H.O.H. and Yamamoto, H.K.T. (2008) Cavernous Lymphangioma of the Lower Lip: Clinicopathological and Immunohistochemical Study. International Journal of Oral-Medical Sciences, 7, 123-127. https://doi.org/10.5466/ijoms.7.123

[8] Filston, H.C. (1994) Hemangiomas, Cystic Hygromas, and Teratomas of the Head and Neck. Seminars in Pediatric Surgery, 3, 147-159.

[9] Grasso, D.L., Pelizzo, G., Zocconi, E. and Schleef, J. (2008) Lymphangiomas of the Head and Neck in Children. Acta Otorhinolaryngologica Italica: Organo Ufficiale della Societa Italiana di Otorinolaringologia e Chirurgia Cervico-Facciale, 28, 17-20. 
[10] Sivasankari, V.U., Jeelani, S., Asokan, G.S. and Parthiban, J. (2014) Lymphangioma of the Tongue-A Case Report and Review of Literature. Journal of Clinical and Diagnostic Research, 8, ZD12-ZD14.

[11] Smith, M.C., Zimmerman, M.B., Burke, D.K., Bauman, N.M., Sato, Y., Smith, R.J., et al. (2009) Efficacy and Safety of OK-432 Immunotherapy of Lymphatic Malformations. The Laryngoscope, 119, 107-115. https://doi.org/10.1002/lary.20041

[12] Rozman, Z.T.R., Zaleha, A.M., Zakaria, Z. and Zulfiqar, M.A. (2011) Lymphangioma: Is Intralesional Bleomycin Sclerotherapy Effective? Biomedical Imaging and Intervention Journal, 7, e18.

Submit or recommend next manuscript to SCIRP and we will provide best service for you:

Accepting pre-submission inquiries through Email, Facebook, LinkedIn, Twitter, etc. A wide selection of journals (inclusive of 9 subjects, more than 200 journals)

Providing 24-hour high-quality service

User-friendly online submission system

Fair and swift peer-review system

Efficient typesetting and proofreading procedure

Display of the result of downloads and visits, as well as the number of cited articles Maximum dissemination of your research work

Submit your manuscript at: http://papersubmission.scirp.org/

Or contact ojst@scirp.org 